\title{
Non-medical use of prescription stimulants among US college students: prevalence and correlates from a national survey
}

\author{
Sean Esteban McCabe', John R. Knight ${ }^{2}$, Christian J. Teter ${ }^{3}$ \& Henry Wechsler ${ }^{4}$ \\ University of Michigan, Substance Abuse Research Center, Ann Arbor, MI,' Harvard Medical School and Children's Hospital Boston, Center for Adolescent \\ Substance Abuse Research, Boston, MA, ${ }^{2}$ Northeastern University, Boeve' College of Health Sciences, McLean Hospital Alcohol and Drug Abuse Treatment \\ Program, Boston, MA $\mathrm{A}^{3}$ and Harvard School of Public Health, Department of Society, Human Development and Health, Boston, MA USA
}

\section{Correspondence to:}

Sean Esteban McCabe

Acting Director and Assistant Research Scientist

University of Michigan

Substance Abuse Research Center

2025 Traverwood Drive

Suite C

Ann Arbor

MI 48105-2194

USA

Tel: (734) 9986510

Fax: (734) 9986508

E-mail: plius@umich.edu

Submitted 10 December 2003;

initial review completed 1 April 2004;

final version accepted 31 August 2004

\begin{abstract}
Aims To examine the prevalence rates and correlates of non-medical use of prescription stimulants (Ritalin, Dexedrine or Adderall) among US college students in terms of student and college characteristics.

Design A self-administered mail survey.

Setting One hundred and nineteen nationally representative 4-year colleges in the United States.

Participants A representative sample of 10904 randomly selected college students in 2001.

Measurements Self-reports of non-medical use of prescription stimulants and other substance use behaviors.

Findings The life-time prevalence of non-medical prescription stimulant use was $6.9 \%$, past year prevalence was $4.1 \%$ and past month prevalence was $2.1 \%$. Past year rates of non-medical use ranged from zero to $25 \%$ at individual colleges. Multivariate regression analyses indicated non-medical use was higher among college students who were male, white, members of fraternities and sororities and earned lower grade point averages. Rates were higher at colleges located in the north-eastern region of the US and colleges with more competitive admission standards. Non-medical prescription stimulant users were more likely to report use of alcohol, cigarettes, marijuana, ecstasy, cocaine and other risky behaviors.

Conclusions The findings of the present study provide evidence that nonmedical use of prescription stimulants is more prevalent among particular subgroups of US college students and types of colleges. The non-medical use of prescription stimulants represents a high-risk behavior that should be monitored further and intervention efforts are needed to curb this form of drug use.
\end{abstract}

KEYWORDS Adderall, ADHD, amphetamines, college students, Dexedrine, methylphenidate, non-medical use, prescription stimulants, Ritalin.

\section{INTRODUCTION}

Methylphenidate, dextroamphetamine and mixed-salts amphetamine are considered first-line pharmacotherapy for the treatment of attention deficit hyperactivity disorder (ADHD) (Greenhill et al. 2002). Brand names for these compounds include Ritalin, Dexedrine and
Adderall, respectively. Several studies have reported recent increases in the prescribing of psychoactive medications in the United States (Olfson et al. 2002; Zito et al. 2003), including amphetamines and other stimulant medications for ADHD (Robison et al. 1999, 2002; Olfson et al. 2003). The rise in these medical prescriptions is due to several factors, including an increased awareness 
regarding the signs and symptoms of certain disorders (e.g. ADHD) (Goldman et al. 1998) and an increased duration of treatment (Safer, Zito \& Fine 1996). In order to put these increased US rates of prescription stimulants into an international perspective, it is important to recognize that the use of prescription stimulants, such as methylphenidate, is higher in the United States than in other countries (Berbatis et al. 2002). Indeed, the United States consumes a majority of the world's supply of methylphenidate (Woodworth 2000). The prevalence of the ADHD diagnosis is also higher in the United States than in other countries (Popper \& West 1999). Furthermore, increases in the use of prescription psychostimulants, such as methylphenidate, have occurred in countries outside the United States as well (Berbatis et al. 2002). The implications of this increased use of prescription stimulants remain to be determined.

Despite the efficacy of prescription stimulants for treating symptoms of $\mathrm{ADHD}$, the increase in prescription rates has raised some public health concerns because of the abuse potential of these medications (Kollins, MacDonald \& Rush 2001) and the evidence that the non-medical use of prescription stimulants represents a problem among young adults in general (Office of Applied Studies 2003; SAMHSA 2003a, 2003b) and among college students in particular (Babcock \& Byrne 2000; Johnston, O’Malley \& Bachman 2003a, 2003b; Teter et al. 2003). National epidemiological studies (Office of Applied Studies 2002a, 2002b; Johnston et al. 2003a, 2003b), national surveillance reports (SAMHSA 2003a, 2003b) and collegebased studies (e.g. Babcock \& Byrne 2000; Teter et al. 2003; McCabe, Teter \& Boyd in press) provide strong evidence that the non-medical use of prescription stimulants is a growing problem among young adults and college students in the United States. The Monitoring the Future Study (MTF) found that college students (5.7\%) reported higher rates of non-medical use of methylphenidate (Ritalin) than their same-age peers not attending college (2.5\%) in the past year (Johnston et al. 2003a).

Several studies have examined the non-medical use of prescription stimulants at individual US colleges or universities using random sampling (e.g. Babcock \& Byrne 2000; Teter et al. 2003; McCabe et al. in press). Collectively, these college-based studies suggest that there may be variation in the non-medical prevalence rate of prescription stimulants across different types of colleges. Although these single institutional studies provide valuable information, they provide only a partial picture of the spectrum of non-medical use of prescription stimulants on college campuses in the United States. We could find no studies that have examined the prevalence and correlates of non-medical use of prescription stimulants among a national sample of college students.
The main aims of the present study were to assess the prevalence of non-medical prescription stimulant use (Ritalin, Dexedrine or Adderall) within a large national sample of randomly selected students attending 4-year colleges and to determine the correlates of non-medical use in terms of demographic characteristics, institutional characteristics and other substance use behaviors.

\section{METHOD}

The present study used data from the 2001 College Alcohol Study (CAS) survey of 119 American 4-year colleges and universities in 39 states. An administrator from each college or university provided a list of 215 randomly selected college students. One school was excluded because the response rate was considerably lower than the other 119 schools. A total of 10904 students returned questionnaires, yielding an overall response rate of approximately 52\% (range 22-86\%). Response rate was not associated with the main outcome variable (i.e. the Pearson correlation coefficient between the non-medical use of stimulant medication and the response rate at the college-level was 0.12 in absolute value with $P=0.19$ ). Consistent with previous studies, the data were weighted based on gender, age and ethnicity in order to be more representative of each school. Study design and procedures are described in more detail elsewhere (Wechsler et al. 2002).

The final sample of 119 colleges represented a national cross-section of students enrolled at 4-year colleges in the United States. Sixty-nine per cent of students in the CAS sample attended public institutions and 31\% attended private institutions, which closely resembles the US national distribution of $68 \%$ and $32 \%$, respectively, for full-time, 4-year college students. Sixty-nine per cent of students in the CAS sample attended schools in medium- to large-sized cities and 31\% attended colleges in small towns and rural areas, which approximates the US national distribution of $71 \%$ and $29 \%$, respectively. Eighty-seven per cent of students in the CAS sample attended non-religiously affiliated colleges and $13 \%$ attended religiously affiliated schools compared to $84 \%$ and $16 \%$ of full-time, 4-year college students nation-wide. In addition, $47 \%$ of students in the CAS sample attended large institutions (>10 000 students), $23 \%$ medium-sized institutions (5001-10 000 students) and 29\% small institutions (1000-5000 students). Twenty-three per cent of students in the CAS sample attended schools located in the North-east, 29\% in the South, 30\% in the North Central and 18\% in the West. Finally, $5 \%$ of students in the CAS sample attended women's colleges and 2\% attended historically black colleges and universities. 


\section{The questionnaire and measures}

Students completed a 20-page survey, which contained questions regarding demographic characteristics, substance use and other health behaviors.

\section{Non-medical use of prescription stimulants}

Respondents were asked 'How often, if ever, have you used any of the drugs listed below? Do not include anything you used under a doctor's orders.' Drug items included 'Ritalin, Dexedrine or Adderall.' The response scale was (1) never used; (2) used, but not in the past 12 months; (3) used, but not in the past 30 days; and (4) used in the past 30 days.

\section{Illicit drug use}

Respondents were asked 'How often, if ever, have you used any of the drugs listed below? Do not include anything you used under a doctor's orders.' Drug items included each of the following: 'marijuana, crack cocaine, other forms of cocaine, ecstasy (MDMA) and opiate-type prescription drugs (e.g. codeine, morphine, Demerol, Percodan, Percocet, Vicodin, Darvon, Darvocet).' The response scale ranged from (1) never used to (4) used in the past 30 days.

\section{Cigarette use}

Respondents were asked 'How often, if ever, have you used any of the drugs listed below? Do not include anything you used under a doctor's orders.' Drug items included 'cigarettes.' The response scale ranged from (1) never used to (4) used in the past 30 days.

\section{Alcohol use}

Heavy episodic drinking (or binge drinking) was defined as the consumption of at least five drinks in a row for men and at least four drinks in a row for women during the 2 weeks preceding completion of the questionnaire (Wechsler et al. 1995). 'Frequent binge drinking' was defined as having three or more binge drinking episodes in the past 2 weeks. 'Drink to get drunk' was assessed with one item that asked students whether drinking 'to get drunk' was an important reason to drink alcohol.

\section{Data analysis}

Data analysis included 10904 undergraduate student respondents from 119 institutions. Statistical analyses were carried out using procedures available in the Stata software package for analysis of complex sample survey data (StataCorp 2001). Data were weighted to account for colleges' varying sampling fractions. We used contingency tables to present the prevalence estimates of nonmedical use of prescription stimulants in terms of student and college characteristics. Differences among the prevalence of non-medical use between student and college characteristics were compared using Pearson's $\chi^{2}$ statistics corrected for the survey clustered design. Pearson's $\chi^{2}$ tests were conducted for the following individual-level characteristics (gender, race, Hispanic ethnicity, age, living arrangement, fraternity/sorority membership, grade point average, father's level of education, mother's level of education) and college-level characteristics (admissions selectivity, public versus private college, geographical region, commuter status, co-educational status, size of school enrollment, urbanization). Multiple logistic regressions accounting for the complex design of the sample were used to predict the student level outcomes of past year and past month non-medical use of prescription stimulants, while controlling for the individual-level and college-level characteristics that were significantly associated with either past year or past month non-medical use of prescription stimulants according to the bivariate results $(P<0.01)$. Odds ratios were adjusted for gender, race, age, living arrangement, fraternity and sorority membership status, grade point average, mother's educational level, father's educational level, admissions selectivity, geographical region and commuter status; 95\% confidence intervals (CI) were reported for the odds ratios. Interactions between college-level and individuallevel characteristics were examined in the logistic regression models in order to investigate whether the relationships of individual-level characteristics with non-medical use of prescription stimulants varied by college-level characteristics. A similar multivariate approach was used to examine the relationship of non-medical use of prescription stimulants with the likelihood of engaging in various substance use behaviors, adjusting for other factors. We used stata to obtain correct standard errors of the estimated regression coefficients accounting for the clustered design of the sample.

\section{RESULTS}

Prevalence of non-medical use of prescription stimulants by student characteristics

Approximately $6.9 \%(\mathrm{SE}=0.005)$ of college students reported life-time non-medical use of prescription stimulants, $4.1 \%(\mathrm{SE}=0.004)$ reported non-medical use in the past year and $2.1 \%(\mathrm{SE}=0.002)$ reported past month use. As illustrated in Table 1, the past year and past month prevalence of non-medical use of prescription 
Table 1 Prevalence of non-medical use of prescription stimulants by student characteristics, 2001

\begin{tabular}{|c|c|c|c|c|c|}
\hline Student characteristics & $n$ & $\begin{array}{l}\text { Past year use } \\
\%(95 \% \text { CI })\end{array}$ & $\begin{array}{l}\chi^{2} \\
P \text {-value }\end{array}$ & $\begin{array}{l}\text { Past month use } \\
\%(95 \% \text { CI })\end{array}$ & $\begin{array}{l}\chi^{2} \\
P \text {-value }\end{array}$ \\
\hline \multicolumn{6}{|l|}{ Gender } \\
\hline Female & 6952 & $2.9(2.3,3.6)$ & \multirow[t]{2}{*}{$<0.001$} & $1.6(1.2,2.0)$ & \multirow[t]{2}{*}{$<0.001$} \\
\hline Male & 3868 & $5.8(4.6,7.2)$ & & $2.8(2.2,3.7)$ & \\
\hline \multicolumn{6}{|l|}{ Race } \\
\hline White & 8195 & $4.9(4.1,6.0)$ & \multirow[t]{4}{*}{$<0.001$} & $2.5(2.0,3.1)$ & \multirow[t]{4}{*}{$<0.001$} \\
\hline African American & 787 & $1.6(0.6,4.2)$ & & $0.4(0.1,1.3)$ & \\
\hline Asian & 835 & $1.3(0.7,2.6)$ & & $0.7(0.2,2.0)$ & \\
\hline Other & 938 & $3.1(1.9,4.9)$ & & $2.0(0.1,3.4)$ & \\
\hline \multicolumn{6}{|l|}{ Age (years) } \\
\hline Under 21 & 5437 & $4.5(3.6,5.6)$ & \multirow[t]{3}{*}{$<0.001$} & $2.5(1.9,3.2)$ & \multirow[t]{3}{*}{$<0.01$} \\
\hline $21-23$ & 3959 & $4.5(3.6,5.6)$ & & $2.1(1.5,2.8)$ & \\
\hline 24 or older & 1438 & $1.6(0.9,2.6)$ & & $0.7(0.3,1.7)$ & \\
\hline \multicolumn{6}{|l|}{ Living arrangement } \\
\hline Single-sex residence hall & 1291 & $3.5(2.3,5.5)$ & \multirow[t]{5}{*}{$<0.001$} & $2.0(1.1,3.4)$ & \multirow[t]{5}{*}{$<0.001$} \\
\hline Co-ed residence hall & 2543 & $4.5(3.3,6.2)$ & & $2.5(1.8,3.5)$ & \\
\hline Other university housing & 399 & $4.0(2.3,6.8)$ & & $1.8(0.7,4.4)$ & \\
\hline Fraternity/sorority house & 267 & $13.3(7.8,21.8)$ & & $8.0(4.7,13.3)$ & \\
\hline Off campus house or apartment & 6241 & $3.7(2.9,4.6)$ & & $1.8(1.3,2.3)$ & \\
\hline \multicolumn{6}{|l|}{ Fraternity/sorority membership } \\
\hline Non-member & 9395 & $3.5(2.8,4.4)$ & \multirow[t]{2}{*}{$<0.001$} & $1.8(1.4,2.3)$ & \multirow[t]{2}{*}{$<0.001$} \\
\hline Member & 1331 & $8.6(6.2,11.8)$ & & $4.7(3.2,6.7)$ & \\
\hline \multicolumn{6}{|l|}{ Grade point average } \\
\hline B or lower & 4661 & $5.2(4.2,6.5)$ & \multirow[t]{2}{*}{$<0.001$} & $2.6(2.0,3.4)$ & \multirow[t]{2}{*}{$<0.01$} \\
\hline $\mathrm{B}+$ or higher & 6179 & $3.3(2.6,4.1)$ & & $1.7(1.3,2.2)$ & \\
\hline \multicolumn{6}{|l|}{ Father's level of education } \\
\hline Less than high school diploma & 665 & $1.6(0.7,3.3)$ & \multirow[t]{6}{*}{$<0.001$} & $0.7(0.3,1.9)$ & \multirow[t]{6}{*}{$<0.001$} \\
\hline High school diploma & 1921 & $2.5(1.7,3.6)$ & & $0.9(0.1,1.7)$ & \\
\hline Some college & 2742 & $3.0(2.3,3.9)$ & & $1.4(0.1,2.0)$ & \\
\hline Four year college degree or more & 5185 & $5.7(4.6,7.1)$ & & $3.1(2.4,3.9)$ & \\
\hline Don't know & 144 & $1.5(0.5,4.7)$ & & $1.5(0.1,4.7)$ & \\
\hline Not applicable & 146 & $3.6(0.9,13.2)$ & & $3.0(0.1,13.7)$ & \\
\hline \multicolumn{6}{|l|}{ Mother's level of education } \\
\hline Less than high school diploma & 589 & $2.0(1.0,4.0)$ & \multirow[t]{6}{*}{$<0.001$} & $0.5(0.2,1.7)$ & \multirow[t]{6}{*}{$<0.01$} \\
\hline High school diploma & 2382 & $3.1(2.2,4.3)$ & & $1.5(0.9,2.3)$ & \\
\hline Some college & 3193 & $3.5(2.7,4.5)$ & & $1.7(1.2,2.3)$ & \\
\hline Four year college degree or more & 4514 & $5.5(4.3,6.9)$ & & $3.0(2.3,3.9)$ & \\
\hline Don’t know & 72 & $0.1(<0.1,3.9)$ & & $0.5(<0.1,3.9)$ & \\
\hline Not applicable & 42 & $9.0(1.9,33.2)$ & & $7.1(1.1,34.8)$ & \\
\hline
\end{tabular}

${ }^{a} \chi^{2} P$-values indicate whether percentages are significantly different by student characteristics. The results for individual characteristics that were not significantly $(P<0.01)$ associated with either past year or past month non-medical use of prescription stimulants are not shown and included Hispanic ethnicity.

stimulants differed significantly as a function of several student characteristics including gender, race/ethnicity, age, living arrangement, fraternity/sorority membership, grade point average and parental level of education.

\section{Prevalence of non-medical use of prescription stimulants by college characteristics}

There was a great deal of variation across campuses with respect to the non-medical use of prescription stimulants. As illustrated in Fig. 1, the aggregate past year prevalence rates of non-medical use at individual colleges ranged from $0 \%$ to $25 \%$, with 20 schools having a prevalence of $0 \%$ and 12 schools having a prevalence of $10 \%$ or higher. Based on the overall past year prevalence of $4.1 \%$ and an average college sample size of 90 , the standard error at the typical/average college was approximately $2 \%$. The past month prevalence rates of nonmedical use at individual colleges ranged from $0 \%$ to $13 \%$.

As illustrated in Table 2, the prevalence of past year and past month non-medical use of prescription 


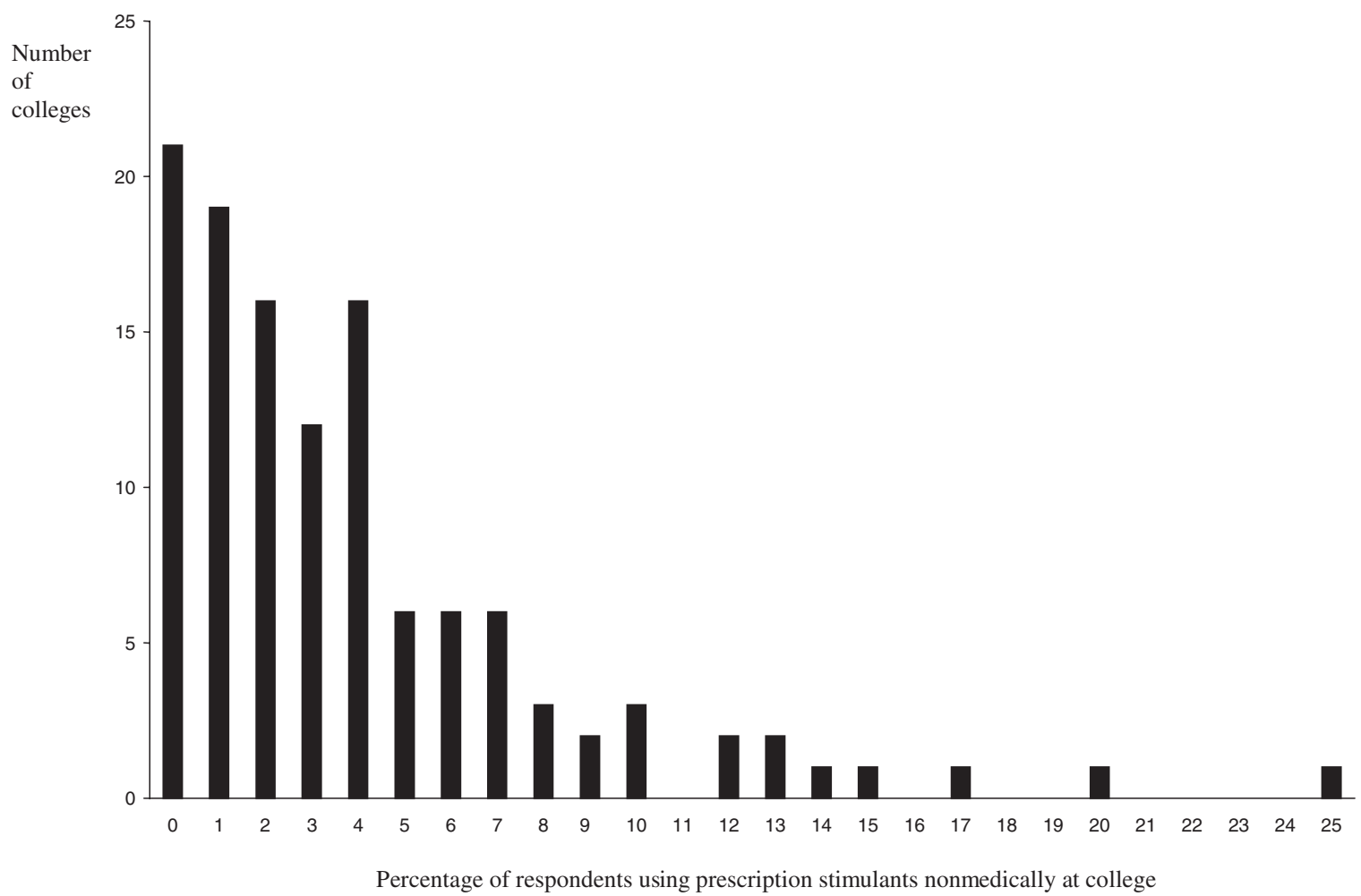

Figure I Distribution of past year non-medical use of prescription stimulants across I I 9 colleges, 200 I

Table 2 Prevalence of non-medical use of prescription stimulants by college characteristics, 2001.

\begin{tabular}{|c|c|c|c|c|c|c|}
\hline Student characteristics & $\begin{array}{l}\text { College } \\
\text { sample } \\
n\end{array}$ & $\begin{array}{l}\text { Student } \\
\text { sample } \\
n\end{array}$ & $\begin{array}{l}\text { Past year } \\
\text { use } \\
\%(95 \% \text { CI })\end{array}$ & $\begin{array}{l}\chi^{2} \\
P \text {-value }\end{array}$ & $\begin{array}{l}\text { Past month } \\
\text { use } \\
\%(95 \% \text { CI })\end{array}$ & $\begin{array}{l}\chi^{2} \\
P \text {-value }\end{array}$ \\
\hline \multicolumn{7}{|l|}{ Admission criteria } \\
\hline Less competitive & 26 & 2288 & $1.3(0.9,2.1)$ & \multirow[t]{3}{*}{$<0.001$} & $0.7(0.4,1.4)$ & \multirow[t]{3}{*}{$<0.01$} \\
\hline Competitive & 71 & 6375 & $4.5(3.6,5.7)$ & & $2.3(1.7,3.0)$ & \\
\hline Most competitive & 22 & 2177 & $5.9(4.0,8.5)$ & & $3.1(2.1,4.4)$ & \\
\hline \multicolumn{7}{|l|}{ Geographical region } \\
\hline North-east & 29 & 2544 & $6.3(4.4,9.0)$ & \multirow[t]{4}{*}{$<0.01$} & $3.1(2.1,4.6)$ & \multirow[t]{4}{*}{$<0.05$} \\
\hline South & 37 & 3162 & $4.6(3.3,6.3)$ & & $2.7(2.0,3.7)$ & \\
\hline North Central & 33 & 3208 & $2.8(2.1,3.8)$ & & $1.3(0.9,1.8)$ & \\
\hline West & 20 & 1926 & $3.2(1.9,5.4)$ & & $1.5(0.8,3.1)$ & \\
\hline \multicolumn{7}{|l|}{ Commuter status } \\
\hline Non-commuter school & 104 & 9499 & $4.6(3.8,5.6)$ & \multirow[t]{2}{*}{$<0.001$} & $2.3(1.8,2.9)$ & \multirow[t]{2}{*}{$<0.01$} \\
\hline Commuter school & 15 & 1341 & $1.2(0.7,1.9)$ & & $0.9(0.4,1.7)$ & \\
\hline
\end{tabular}

${ }^{\mathrm{a}} \chi^{2} \mathrm{P}$-values indicate whether distributions are significantly different by college characteristics. The results for college characteristics that were not significantly $(P<0.01)$ associated with either past year or past month non-medical use of prescription stimulants are not shown and included public versus private college status, co-educational status, size of school enrollment and urbanization.

stimulants differed significantly as a function of admissions selectivity, commuter status and geographical region (past year only). For example, more than $80 \%$ of the colleges with an aggregate past year prevalence rate of $10 \%$ or higher had highly competitive admissions standards and were located either in the North-east or Southern regions of the United States. In addition, among all students attending three historically black colleges in the sample, there were no students who reported nonmedical use of prescription stimulants in the past year.

\section{Multivariate results}

As illustrated in Table 3, logistic regression analyses confirmed that past year and past month non-medical use of prescription stimulants was higher among college 
Table 3 Correlates of non-medical use of prescription stimulants by student and college characteristics. ${ }^{\mathrm{a}}$

\begin{tabular}{|c|c|c|c|c|}
\hline \multirow[b]{2}{*}{ Characteristic } & \multicolumn{2}{|l|}{ Past year } & \multicolumn{2}{|l|}{ Past month } \\
\hline & Adjusted $O R^{\mathrm{b}}$ & $95 \% C I$ & Adjusted $O R^{\mathrm{b}}$ & $95 \% C I$ \\
\hline \multicolumn{5}{|l|}{ Gender } \\
\hline Female & - & - & - & - \\
\hline Male & $1.92^{* * *}$ & $(1.49,2.48)$ & $1.66^{* * *}$ & $(1.24,2.21)$ \\
\hline \multicolumn{5}{|l|}{ Race } \\
\hline White & - & - & - & - \\
\hline African American & 0.39 & $(0.15,1.07)$ & $0.18^{* *}$ & $(0.05,0.62)$ \\
\hline Asian & $0.26^{* * *}$ & $(0.13,0.52)$ & $0.30^{*}$ & $(0.10,0.92)$ \\
\hline Other & 0.75 & $(0.47,1.20)$ & 1.03 & $(0.60,1.67)$ \\
\hline \multicolumn{5}{|c|}{ Fraternity/sorority membership } \\
\hline Non-member & - & - & - & - \\
\hline Member & $2.07^{* * *}$ & $(1.38,3.09)$ & $2.04^{* *}$ & $(1.21,3.45)$ \\
\hline \multicolumn{5}{|l|}{ Grade point average } \\
\hline B or lower & - & - & - & - \\
\hline $\mathrm{B}+$ or higher & $0.54^{* * *}$ & $(0.42,0.70)$ & $0.57^{* * *}$ & $(0.42,0.78)$ \\
\hline \multicolumn{5}{|l|}{ Admission criteria } \\
\hline Less competitive & - & - & - & - \\
\hline Competitive & $2.29^{* *}$ & $(1.34,3.91)$ & 1.88 & $(0.95,3.71)$ \\
\hline Most competitive & $2.57^{* *}$ & $(1.36,4.84)$ & 2.06 & $(0.98,4.34)$ \\
\hline \multicolumn{5}{|l|}{ Geographical region } \\
\hline North-east & - & - & - & - \\
\hline South & 0.68 & $(0.42,1.09)$ & 0.86 & $(0.54,1.39)$ \\
\hline North Central & $0.46^{* *}$ & $(0.30,0.72)$ & $0.44^{* *}$ & $(0.26,0.72)$ \\
\hline West & 0.56 & $(0.30,1.05)$ & 0.52 & $(0.22,1.22)$ \\
\hline
\end{tabular}

${ }^{*} P<0.05,{ }^{* *} P<0.01,{ }^{* * *} P<0.001$. - Reference category. ${ }^{\text {a }}$ The sample size for both models was 10556 cases. ${ }^{b}$ Odds ratios are adjusted for all predictors in both models, which included gender, race, age, living arrangement, mother's level of education, father's level of education, fraternity and sorority membership status, grade point average, admissions selectivity, geographical region and commuter status. The results for variables that were not significantly $(P<0.01)$ associated with either past year or past month non-medical use of prescription stimulants are not shown and included age, living arrangement, mother's level of educational level, father's level of education and commuter status.

students who were male, white, members of fraternities and sororities, had lower grade point averages, attended colleges located in the North-eastern region of the United States and attended more selective colleges (past year only). Specifically, after adjusting for other factors, college men were almost two times more likely than women to report non-medical use of prescription stimulants. In addition, white students were more likely than Asian and African American students to report non-medical use. Fraternity and sorority members were over two times more likely than non-members to report non-medical use of prescription stimulants. Students who earned a B or lower grade point average were almost two times more likely to report non-medical use compared to students who earned a B + or higher. In terms of college characteristics, students attending colleges located in the Northeastern region of the United States were more likely to report non-medical use than students attending colleges located in North Central region of the United States. Finally, students who attended colleges with competitive or highly competitive admissions criteria were over two times more likely than students who attended less com- petitive colleges to report past year non-medical use of prescription stimulants.

Interactions between college-level and individuallevel characteristics were examined in the multiple logistic regression models in order to investigate whether the relationships of individual-level risk factors that significantly predicted non-medical use of prescription stimulants in Table 3 varied by college-level characteristics (results not shown). There were no significant interactions for past month non-medical use and only one significant interaction was found for past year non-medical use. In particular, attending college in the North Central United States served as a stronger risk factor for nonmembers of fraternities and sororities relative to members for past year non-medical use $(P=0.005)$.

Interactions between individual-level characteristics were also examined and very few were found. There were no significant interactions for past month non-medical use and only one statistically significant interaction was found for past year non-medical use. Being African American served as a stronger risk factor for past year non-medical use of prescription stimulants in fraternity/ 
Table 4 Substance use behaviors associated with past year non-medical use of prescription stimulants. ${ }^{\mathrm{a}}$

\begin{tabular}{|c|c|c|c|c|}
\hline Substance use behaviors & $\begin{array}{l}\text { Non-medical use } \\
(n=422) \\
\%(95 \% \text { CI })\end{array}$ & $\begin{array}{l}\text { No non-medical use } \\
(n=10399) \\
\%(95 \% \mathrm{CI})\end{array}$ & Adjusted $O R^{\mathrm{b}, \mathrm{c}}$ & $95 \% C I$ \\
\hline \multicolumn{5}{|l|}{ Tobacco and alcohol use } \\
\hline Cigarette use in the past 30 days & $66.7(61.7,71.4)$ & $23.6(22.0,25.2)$ & $6.15^{* * *}$ & $(4.88,7.76)$ \\
\hline Frequent binge drinking & $69.4(63.0,75.1)$ & $20.6(18.7,22.6)$ & $6.75^{* * *}$ & $(5.01,9.08)$ \\
\hline Drink to get drunk & $80.8(76.2,84.7)$ & $46.8(44.7,49.0)$ & $3.79^{* * *}$ & $(2.85,5.04)$ \\
\hline \multicolumn{5}{|l|}{ Drug use in the past 30 days } \\
\hline Marijuana & $67.8(62.5,72.8)$ & $14.6(13.4,15.8)$ & $10.59^{* * *}$ & $(8.16,13.73)$ \\
\hline Ecstasy & $18.9(14.5,24.3)$ & $1.3(1.1,1.7)$ & $16.50^{* * *}$ & $(11.06,24.62)$ \\
\hline Cocaine & $17.3(13.8,21.5)$ & $0.9(0.7,1.1)$ & $19.70^{* * *}$ & $(13.36,29.05)$ \\
\hline Opiates (other than heroin) & $19.4(15.7,23.7)$ & $2.1(1.8,2.5)$ & $10.58^{* * *}$ & $(7.85-14.26)$ \\
\hline \multicolumn{5}{|l|}{ Drug use in the past year } \\
\hline Marijuana & $84.6(80.0,88.4)$ & $27.3(25.5,29.1)$ & $12.29^{* * *}$ & $(8.86,17.06)$ \\
\hline Ecstasy & $51.7(46.1,57.2)$ & $5.1(4.5,5.9)$ & $17.96^{* * *}$ & $(13.63,23.67)$ \\
\hline Cocaine & $34.6(29.2,40.4)$ & $2.3(1.9,2.7)$ & $22.02^{* * *}$ & $(15.84,30.61)$ \\
\hline Opiates (other than heroin) & $44.2(39.2,49.3)$ & $5.5(4.9,6.2)$ & $13.00^{* * * *}$ & $(9.99,16.93)$ \\
\hline \multicolumn{5}{|l|}{ Other risky behaviors } \\
\hline Drove after binge drinking & $35.2(29.4,41.4)$ & $9.4(8.1,10.8)$ & $5.37^{* * *}$ & $(4.09,7.04)$ \\
\hline Passenger with a drunk driver & $66.0(60.5,71.1)$ & $21.3(19.7,23.1)$ & $6.83^{* * *}$ & $(5.38,8.69)$ \\
\hline Drove after drinking & $58.7(51.6,65.4)$ & $26.9(24.7,29.2)$ & $4.03^{* * *}$ & $(2.98,5.45)$ \\
\hline
\end{tabular}

${ }^{* * *} P<0.001$. aThe sample sizes for logistic regression models ranged from 10474 to 10555 with the exception of 'drink to get drunk', which was based on only those who consumed alcohol in the past 30 days $(n=8576)$. 'odds ratios are also adjusted for gender, race, age, living arrangement, parental education, fraternity/sorority membership, grade point average, geographical region, commuter status and admissions selectivity. The results for these variables are not shown. ${ }^{c}$ The reference group for each logistic regression model was students who did not report non-medical use of prescription stimulants in the past year.

sorority members compared to non-members $(P=0.007)$.

\section{The relationship of non-medical use of prescription stimulants to other substance use}

As illustrated in Table 4, non-medical use of prescription stimulants was highly related to substance use and other risky behaviors after adjusting for the same factors in Table 3. For instance, past year non-medical prescription stimulant users were ten times more likely to report marijuana use in the past year, almost seven times more likely to report frequent binge drinking, over 20 times more likely to report cocaine use in the past year, and over five times more likely to report driving after binge drinking than college students who had not used prescription stimulants non-medically. Results were similar for the relationship between past month non-medical use and other drug use (results not shown).

At the college-level of analysis, the correlation of nonmedical prescription stimulant use and substance use at the 119 colleges and universities was examined. The correlation between a school's past year aggregate rate of non-medical use of prescription stimulants and marijuana use in the past year was $r=0.55(P<0.001)$. The correlation between a school's past year aggregate level of non-medical use of prescription stimulants and aggregate level of binge drinking was $r=0.52(P<0.001)$. Finally, college campuses with high (over $50 \%$ ) or medium (36$50 \%$ ) aggregate levels of binge drinking had significantly higher past year aggregate rates of non-medical prescription stimulant use than schools with lower (35\% or less) aggregate levels of binge drinking $(6 \%, 5 \%$ and $1 \%$, respectively, $P<0.001)$.

\section{DISCUSSION}

The present study found that the population of US college students reporting life-time non-medical use of prescription stimulants was $6.9 \%$, past year use was $4.1 \%$ and past month use was $2.1 \%$. These prevalence rates are similar to recent rates from other national studies of college students (e.g. Johnston et al. 2003a) and young adults (Office of Applied Studies 2002a, 2002b). Nonmedical prescription stimulant use was higher among certain types of college students, in particular among men, white students, members of fraternities and sororities and those with lower grade point averages. Collectively, many of these individual-level characteristics have been shown previously to be associated with higher rates of substance use among American college 
students such as heavy episodic drinking (e.g. Cashin, Presley \& Meilman 1998; Wechsler et al. 2000; Wechsler etal. 2002), marijuana use (e.g. Bell, Wechsler \& Johnston 1997; Gledhill-Hoyt et al. 2000), and ecstasy use (e.g. Strote, Lee \& Wechsler 2002; Yacoubian 2003),

At least two other studies have shown that undergraduate college men were more likely than women to report non-medical use of prescription stimulants (Johnston et al. 2003a; McCabe et al. in press). Despite gender differences in prevalence of non-medical use, the results of the present study indicated that risk factors for non-medical use of prescription stimulants generally operated in a similar way for women and men. The higher rates of nonmedical prescription stimulant use found among white college students compared to other racial groups is consistent with racial differences in non-medical use of prescription stimulants among college students (McCabe $e t$ al. in press) as well as racial differences found in the prescription rates for stimulant medications (e.g. LeFever, Dawson \& Morrow 1999; Safer \& Malever 2000; Cox et al. 2003; Zito et al. 2003; McCabe et al. in press). Finally, the higher non-medical rates of prescription stimulants use among members of social sororities and fraternities are consistent with studies that have found higher prevalence rates of other drug use among students who belong to these organizations (e.g. Bell, Wechsler \& Johnston 1997; Wechsler et al. 2002; Yacoubian 2003).

Consistent with previous studies examining other illicit drug use, the non-medical use of prescription stimulants varied across different types of colleges and universities (Bell et al. 1997; Gledhill-Hoyt et al. 2000; Strote et al. 2002). In the present study, the annual non-medical use of prescription stimulants had a wide range across schools from zero per cent at the lowest to $25 \%$ at the highest. The variation in non-medical use was consistent with differences observed across previous single institution studies and reinforces the value of collecting representative samples from multiple colleges and universities. The present study found similar geographical patterns of non-medical use of prescription stimulants, as was found in the MTF study among young adults ages 19-30, with the highest annual rates of non-medical methylphenidate use found among young adults residing in the Northeastern region of the United States (Johnston et al. 2003a). The high prevalence rates found among colleges in the North-eastern region of the United States also resembles at least two single institution studies that found high rates of non-medical use of prescription stimulants at small colleges in the North-east (Babcock \& Byrne 2000; Low \& Gendaszek 2002).

Taken together, the findings that associate higher rates of non-medical prescription stimulant use with more competitive admissions standards as well as frater- nity/sorority membership suggest these factors are serving collectively as a proxy for higher socio-economic status. Indeed, at least one study has found that undergraduate students with higher family incomes reported higher rates of non-medical prescription stimulant use (Teter et al. 2003).

The present study found that non-medical users of prescription stimulants were dramatically more likely to use other drugs and engage in other risky behaviors, which is consistent with at least three other college-based studies (Teter et al. 2003; McCabe et al. in press; Teter et al. in press). In addition, Teter et al. in press) found the most prevalent motivations for non-medical use of prescription stimulants among college students were to improve concentration, enhance alertness and to get high. Over $50 \%$ of non-medical users reported using prescription stimulants to get high and substance use rates were significantly higher among non-medical users than non-users, regardless of motivation for non-medical use (Teter et al. in press). The higher rates of substance use and other risky behaviors found among non-medical prescription stimulant users may be an indication that the non-medical use of prescription stimulants is part of a larger cluster of problem behaviors among college students (Jessor, Donovan \& Costa 1991).

Several anecdotal case reports document the possible consequences of non-medical use of stimulants (e.g. Parran \& Jasinski 1991; Massello \& Carpenter 1999; Barrett \& Pihl 2002). Epidemiological studies have found that a significant proportion of non-medical prescription stimulant users develop problem use and dependence behaviors (Zacny et al. 2003; Simoni-Wastila \& Strickler 2004). In addition, McCabe et al. in press) found in a random sample of 9161 undergraduate students that over $90 \%$ of non-medical users of prescription stimulants who reported a source indicated they obtained prescription stimulants from peers and friends (McCabe et al. 2004b). In these cases, the non-medical user is likely to be unaware of the stimulant's potential for interaction with other drugs or, alternatively, the drug's documented contraindications and precautions.

\section{Limitations}

The 2001 CAS did not measure legitimate medical use of prescription stimulants or diagnosis, so it was not possible to assess how many students with legitimate prescriptions for stimulants may have misused their own or someone else's stimulant medication. As the data were cross-sectional, inferences about causality are limited and we could not assess whether certain factors preceded initiation of non-medical use of prescription stimulants. Longitudinal data are needed to further examine the directionality of these associations. Additional research is 
needed to ascertain the behavioral patterns that lead to the high rates of non-medical use of prescription stimulants. Finally, the present study probably underestimates the extent of non-medical psychostimulant use on US college campuses because we focused exclusively on three stimulants (e.g. Ritalin, Dexedrine or Adderall) and did not examine the non-medical use of other methylphenidate formulations (e.g. Concerta) or other dextroamphetamine formulations (e.g. Dextrostat).

The CAS is subject to the limitations of self-report surveys. However, such surveys have been used widely and are considered generally valid in examining substance use when certain conditions of confidentiality are met (O’Malley, Bachman \& Johnston 1983; Johnston \& O’Malley 1985; Harrison \& Hughes 1997; O'Malley \& Johnston 2002). For instance, it was made clear to students in the present study that participation was voluntary, the relevance of the study was explained, and respondents were assured that their responses would remain anonymous. Next, non-response may have introduced potential bias in the present study. While we can never fully eliminate the possibility of bias introduced through non-response, we tried to minimize its impact through weighting procedures. In addition, we examined the impact of the response rate and found no significant relationship between response rate and the prevalence rates of non-medical use of stimulant medication. Furthermore, the prevalence rates of non-medical use of prescription stimulants reported in this study are comparable to rates found in other national substance use surveys of US young adults and college students (Johnston et al. 2003a, 2003b; Office of Applied Studies 2002a, 2002b). Finally, the study sample consisted of students attending 4-year US colleges and is not necessarily representative of all US college students, including those attending 2-year colleges. Therefore, our results may not be generalizable to the entire US college population or university students in other countries.

\section{Future practice}

Despite their potential for abuse, prescription stimulants remain a highly effective and safe medication for the majority of individuals with ADHD. At least one study has examined the prevalence rates of prescribed college stimulant users being approached to divert their stimulant medication (McCabe et al. in press). Of the undergraduate students who were medically prescribed stimulant medication for ADHD, approximately 54\% had been approached to divert their medication (e.g. sell, trade or give away) in the past year which was higher than previous investigations of secondary school students (e.g. Musser et al. 1998; McCabe et al. 2004). Collegiate environments present unique challenges to implementing social control strategies compared to elementary and secondary schools because most college students are adults who are responsible for their own care, and parents or school officials are not as available to provide supervision of medications. One possible means of reducing diversion and abuse is the use of novel pharmaceutical delivery systems that are less prone to abuse (e.g. Concerta). Additionally, appropriate diagnosis, treatment and therapeutic monitoring of college students who are receiving prescription psychostimulants is crucial, not only to improve clinical outcomes but also to help prevent the abuse of these medications within a population that is largely responsible for their own medication management.

\section{Future research}

Given the proven therapeutic efficacy of prescription stimulants for the treatment of ADHD (Goldman et al. 1998), there is a need to balance the medical necessity of these drugs and the risk for non-medical use among adolescents and young adults. Future research should be conducted to better categorize non-medical users and examine how prescription stimulants are diverted to non-medical use. Further research is also needed to examine additional individual and contextual variables that might be associated with non-medical use of prescription stimulants, such as diagnosis of ADHD, route of administration and motivations for non-medical use. Finally, the present study focused exclusively on college students within the United States. Research is needed to examine whether the findings from this study generalize to other countries. International work is particularly important, as it is not known whether the higher prevalence rates of $\mathrm{ADHD}$ and the use of prescription psychostimulants in the United States are correlated with the increased non-medical use of these medications. Therefore, it is unclear if countries outside the United States are at less risk for the non-medical use of prescription stimulants.

While the national prevalence of drinking among US college students has remained steady for the past decade, the non-medical use of several prescription drugs has increased among college students (GledhillHoyt et al. 2000; Wechsler et al. 2002; Johnston et al. 2003a; Mohler-Kuo, Lee \& Wechsler 2003). The nonmedical use of prescription medications among college students is second only to marijuana as the most common form of illicit drug use (Johnston et al. 2003a). Findings from the present study provide additional support to the hypothesis that the non-medical use of prescription stimulants represents a problem within some subgroups of college students that needs to be addressed with effective prevention efforts. 


\section{Acknowledgements}

The College Alcohol Study data were collected under a research grant from the Robert Wood Johnson Foundation. The development of this manuscript was supported in part by a National Research Service Award T32 DA 07267 (to Sean Esteban McCabe and Christian J. Teter) from the National Institute on Drug Abuse. The authors would like to thank Jeff Hansen and Mark Seibring for their assistance in preparation of the data and Hannah d'Arcy, Meichun Kuo and Brady West for their consultation in analyzing the data. The authors would also like to thank the students and school personnel for their participation in the study.

\section{References}

Babcock, Q. \& Byrne, T. (2000) Student perceptions of methylphenidate abuse at a public liberal arts college. Journal of American College Health, 49, 143-145.

Barrett, S. P. \& Pihl, R. O. (2002) Oral methylphenidate-alcohol co-abuse. Journal of Clinical Psychopharmacology, 22, 633634.

Bell, R., Wechsler, H. \& Johnston, L. D. (1997) Correlates of college student marijuana use: results of a US National Survey. Addiction, 92, 571-581.

Berbatis, C. G., Sunderland, V. B. \& Bulsara, M. (2002) Licit psychostimulant consumption in Australia, 1984-2000: international and jurisdictional comparison. Medical Journal of Australia, 177, 539-543.

Cashin, J. R., Presley, C. A. \& Meilman, P. W. (1998) Alcohol use in the Greek system: follow the leader? Journal of Studies on Alcohol, 59, 63-70.

Cox, E. R., Motheral, B. R., Henderson, R. R. \& Mager, D. (2003) Geographic variation in the prevalence of stimulant medication use among children 5-14 years old: results from a commercially insured US sample. Pediatrics, 111, 237243.

Gledhill-Hoyt, J., Lee, H., Strote, J. \& Wechsler, H. (2000) Increased use of marijuana and other illicit drugs at US colleges in the 1990s: results of three national surveys. Addiction, 95, 1655-1667.

Goldman, L. S., Genel, M., Bezman, R. J. \& Slanetz, P. J. (1998) Diagnosis and treatment of attention-deficit/hyperactivity disorder in children and adolescents. Council on Scientific Affairs, American Medical Association. JAMA, 279, 11001107.

Greenhill, L. L., Pliszka, S., Dulcan, M. K., Bernet, W., Arnold, V., Beitchman, J., Benson, R. S., Bukstein, O., Kinlan, J., McClellan, J., Rue, D., Shaw, J. A. \& Stock, S. (2002) Practice parameter for the use of stimulant medications in the treatment of children, adolescents, and adults. Journal of the American Academy of Child and Adolescent Psychiatry, 41, 26S-49S.

Harrison, L. \& Hughes, A. (1997) The Validity of Self-Reported Drug Use: Improving the Accuracy of Survey Estimate. NIH publication 97-4147, NIDA Research Monograph no. 167. Washington: Government Printing Office.

Jessor, R., Donovan, J. E. \& Costa, F. M. (1991) Beyond Adolescence: Problem Behavior and Young Adult Development. Cambridge, UK: Cambridge University Press.
Johnston, L. D. \& O'Malley, P. M. (1985) Issues of validity and population coverage in student surveys of drug use. NIDA Research Monograph, 57, 31-54.

Johnston, L. D., O'Malley, P. M. \& Bachman, J. G. (2003a) Monitoring the Future National Survey Results on Drug Use, 19752002: II. College Students and Adults Ages 19-40. NIH publication no. 03-5376. Washington, DC: US Department of Health and Human Services.

Johnston, L. D., O'Malley, P. M. \& Bachman, J. G. (2003b) Monitoring the Future National Survey Results on Drug Use, 19752002: I Secondary School Students. NIH Publication no. 035375. Washington, DC: US Department of Health and Human Services.

Kollins, S. H., MacDonald, E. K. \& Rush, C. R. (2001) Assessing the abuse potential of methylphenidate in nonhuman and human subjects: a review. Pharmacology, Biochemistry and Behavior, 68, 611-627.

LeFever, G. B., Dawson, K. V. \& Morrow, A. L. (1999) The extent of drug therapy for attention deficit-hyperactivity disorder among children in public schools. American Journal of Public Health, 89, 1359-1364.

Low, K. G. \& Gendaszek, A. E. (2002) Illicit use of psychostimulants among college students: a preliminary study. Psychology, Health, and Medicine, 7, 283-287.

Massello, W. 3rd \& Carpenter, D. A. (1999) A fatality due to the intranasal abuse of methylphenidate (Ritalin). Journal of Forensic Sciences, 44, 220-221.

McCabe, S. E., Teter, C. J. \& Boyd, C. J. (2004) The use, misuse and diversion of prescription stimulants among middle and high school students. Substance Use and Misuse, 39, 10951117 .

McCabe, S. E., Teter, C. J. \& Boyd, C. J. (in press) Medical use, illicit use and diversion of prescription stimulant medication. Journal of Psychoactive Drugs, in press.

Mohler-Kuo, M., Lee, J. E. \& Wechsler, H. (2003) Trends in marijuana and other illicit drug use among college students: results from 4 Harvard School of Public Health College Alcohol Study surveys: 1993-2001. Journal of American College Health, 52, 17-24.

Musser, C. J., Ahmann, P. A., Theye, F. W., Mundt, P., Broste, S. K. \& Mueller-Rizner, N. (1998) Stimulant use and the potential for abuse in Wisconsin as reported by school administrators and longitudinally followed children. Journal of Developmental and Behavioral Pediatrics, 19, 187-192.

O’Malley, P. M., Bachman, J. G. \& Johnston, L. D. (1983) Reliability and consistency in self-reports of drug use. International Journal of the Addictions, 18, 805-824.

O’Malley, P. M. \& Johnston, L. D. (2002) Epidemiology of alcohol and other drug use among American college students. Journal of Studies on Alcohol Supplement, 14, 23-39.

Office of Applied Studies (2002a) Results from the 2001 National Household Survey on Drug Abuse: I. Summary of National Findings. DHHS publication no. SMA 02-3758, NHSDA. Series H17. Rockville, MD: Substance Abuse and Mental Health Services Administration.

Office of Applied Studies (2002b) Results from the 2001 National Household Survey on Drug Abuse: III. Detailed Tables. Rockville, MD: Substance Abuse and Mental Health Services Administration.

Office of Applied Studies (2003) Results from the 2002 National Survey on Drug Use and Health: National Findings. DHHS publication no. SMA 03-3836, NHSDA. Series H-22. Rockville, MD: Substance Abuse and Mental Health Services Administration. 
Olfson, M., Gameroff, M. J., Marcus, S. C. \& Jensen, P. S. (2003) National trends in the treatment of attention deficit hyperactivity disorder. American Journal of Psychiatry, 160, 10711077.

Olfson, M., Marcus, S. C., Druss, B. \& Pincus, H. A. (2002) National trends in the use of outpatient psychotherapy. American Journal of Psychiatry, 159, 1914-1920.

Parran, T. V. Jr \& Jasinski, D. R. (1991) Intravenous methylphenidate abuse. Prototype for prescription drug abuse. Archives of Internal Medicine, 151, 781-783.

Popper, C. \& West, S. A. (1999) Disorders usually first diagnosed in infancy, childhood, or adolescence. In: Hales, R. E., Yudofsky, S. \& Talbott, J. A., eds. Textbook of Psychiatry, 3rd edn, chapter 23, pp. 825-954. Washington, DC: American Psychiatric Press.

Robison, L. M., Sclar, D. A., Skaer, T. L. \& Galin, R. S. (1999) National trends in the prevalence of attention-deficit/ hyperactivity disorder and the prescribing of methylphenidate among school-age children: 1990-95. Clinical Pediatrics, 38, 209-217.

Robison, L. M., Skaer, T. L., Sclar, D. A. \& Galin, R. S. (2002) Is attention deficit hyperactivity disorder increasing among girls in the US? Trends in diagnosis and the prescribing of stimulants. CNS Drugs, 16, 129-137.

Safer, D. J. \& Malever, M. (2000) Stimulant treatment in Maryland public schools. Pediatrics, 106, 533-539.

Safer, D. J., Zito, J. M. \& Fine, E. M. (1996) Increased methylphenidate usage for attention deficit disorder in the 1990s. Pediatrics, 98, 1084-1088.

Simoni-Wastila, L. \& Strickler, G. (2004) Risk factors associated with problem use of prescription drugs. American Journal of Public Health, 94, 266-268.

StataCorp (2001) Stata Statistical Software: Release 7.0. College Station, TX: Stata Corporation.

Strote, J., Lee, J. E. \& Wechsler, H. (2002) Increasing MDMA use among college students: results of a national survey. Journal of Adolescent Health, 30, 64-72.

Substance Abuse and Mental Health Services Administration (2003a) Emergency Department Trends from the Drug Abuse Warning Network, Final Estimates 1995-2002, Table 2.6.0. DAWN Series: D-24, DHHS publication no. (SMA) 03-3780. Rockville, MD: Office of Applied Studies.

Substance Abuse and Mental Health Services Administration (2003b) Emergency Department Trends from the Drug Abuse
Warning Network, Final Estimates 1995-2002, Table 2.8.0. DAWN Series: D-24, DHHS publication no. (SMA) 03-3780. Rockville, MD: Office of Applied Studies.

Teter, C. J., McCabe, S. E., Boyd, C. J. \& Guthrie, S. K. (2003) Illicit methylphenidate use in an undergraduate student sample: prevalence and risk factors. Pharmacotherapy, 23, 609-617.

Teter, C. J., McCabe, S. E., Cranford, J. A., Boyd, C. J. \& Guthrie, S. K. (in press) Prevalence and motivations for the illicit use of prescription stimulants in an undergraduate student sample. Journal of American College Health, in press.

University of Florida (2002) University of Florida Alcohol and Drug Survey Key Findings. Campus Alcohol and Drug Resource Center. Available at: http://www.health.ufl.edu/shcc/ drugstat.htm [Accessed 20 August 2003].

Wechsler, H., Dowdall, G. W., Davenport, A. \& Rimm, E. B. (1995) A gender-specific measure of binge drinking among college students. American Journal of Public Health, 85, 982-985.

Wechsler, H., Lee, J. E., Kuo, M. \& Lee, H. (2000) College binge drinking in the 1990s: a continuing problem. Results of the Harvard School of Public Health 1999 College Alcohol Study. Journal of American College Health, 48, 199-210.

Wechsler, H., Lee, J. E., Kuo, M., Seibring, M., Nelson, T. F. \& Lee, H. (2002) Trends in college binge drinking during a period of increased prevention efforts. Findings from 4 Harvard School of Public Health College Alcohol Study surveys: 1993-2001. Journal of American College Health, 50, 203-217.

Woodworth, T. (2000) DEA Congressional Testimony, Committee on Education and the Workforce: Subcommittee on Early Childhood, Youth and Families, 16 May 2000. Available at: http://www.dea.gov/pubs/cngrtest/ct051600.htm [Accessed 18 May 2004].

Yacoubian, G. S. Jr (2003) Correlates of ecstasy use among students surveyed through the 1997 College Alcohol Study. Journal of Drug Education, 33, 61-69.

Zacny, J., Bigelow, G., Compton, P., Foley, K., Iguchi, M. \& Sannerud, C. (2003) College on Problems of Drug Dependence taskforce on prescription opioid non-medical use and abuse: position statement. Drug and Alcohol Dependence, 69, 215232.

Zito, J. M., Safer, D. J., DosReis, S., Gardner, J. F., Magder, L., Soeken, K., Boles, M., Lynch, F. \& Riddle, M. A. (2003) Psychotropic practice patterns for youth: a 10-year perspective. Archives of Pediatrics and Adolescent Medicine, 157, 1725. 